\title{
Detection of additional primary malignant tumor in cancer survivors: the use of PET/ CT for image-guided biopsy
}

\author{
Ekhlas Shaban *iD and Rasha Saleh
}

\begin{abstract}
Background: PET/CT is a well-established tool in the diagnostic workup of oncology patients. With the advance in diagnosis and therapy of oncology patients, survivors are at risk of developing additional malignancies. This study aimed to evaluate the yield of 18F-FDG PET/CT in biopsy guidance for the detection of unexpected additional primary malignancies in patients with known primary cancers. Medical records of patients underwent 18F-FDG PET/ CT scans from July 2015 to December 2017 were reviewed, and 644 patients (346 men and 298 women; mean age 59.7, age range from 21: 78) who had been scanned for known cancers were included in this study. Lesions that were newly detected on PET/CT had not been previously detected by other modalities and were atypical in location for metastases were interpreted as suggestive of a new primary malignant tumor. These image findings guide the biopsy for histopathology, immune-histochemistry to confirm the diagnosis.

Results: PET-positive findings suggestive of new primary malignant tumors were found in 30 (4.67\%) of 644 patients. In 21 (3.26\%) of 644 patients, these lesions were pathologically proven to be malignant (20 true positive and 1 case false negative). Proven sites were lung (5 cases), colorectal (5 cases), breast ( 2 case), liver (2 cases), head and neck (2 cases), anal (1 cases), gastric (1 case), lymphoma (1 case), esophagus (1 case), and prostate (1 case). In 9/30 (30\%) patients suspected to have additional primary, PET was falsely positive. Biopsy was taken for histology and immune-histochemistry with follow-up record that confirms the diagnosis to validate the PET/CT findings.

Conclusions: With the use of 18-F FDG PET/CT image- guided biopsy, additional primary malignancies were detected in at least 3.26\% of oncology patients; thus, patient cure is possible if such malignancies are treated promptly and aggressively.
\end{abstract}

\section{Background}

The number of cancer survivors continues to increase because of the growth and increase life span of the population as well as advances in early detection and treatment. Consequently, the incidence of multiple primary cancers is increasing. Development of additional primary cancers may be attributed to remote side effects of chemotherapy and/or radiation therapy, persisting effect of genetic defects, hormonal factors, and environmental influences and behavioral risk factors $[1,2]$.

\footnotetext{
* Correspondence: ekhlas_radiology@med.tanta.edu.eg

Faculty of Medicine, Tanta University, Egypt, Algeish St, Tanta 31527, Egypt
}

Surveillance, Epidemiology, and End Results (SEER) Program and the International Association of Cancer Registries and International Agency for Research on Cancer (IACR/IARC) define multiple primary tumors as more than one, synchronous or metachronous lesion in the same individual with distinct histopathology [3]. Overall reported frequency of multiple primary cancers varies between $2.4 \%$ and $17 \%$ [2].

Diagnosis of an unsuspected additional malignancy is a challenge. It has a significant impact on a patient's treatment plan and prognosis, and misinterpretation of these findings as metastatic lesions can lead to incorrect upstaging of the primary tumor [4].
Springer Open (c) The Author(s). 2020 Open Access This article is licensed under a Creative Commons Attribution 4.0 International License, which permits use, sharing, adaptation, distribution and reproduction in any medium or format, as long as you give appropriate credit to the original author(s) and the source, provide a link to the Creative Commons licence, and indicate if changes were made. The images or other third party material in this article are included in the article's Creative Commons licence, unless indicated otherwise in a credit line to the material. If material is not included in the article's Creative Commons licence and your intended use is not permitted by statutory regulation or exceeds the permitted use, you will need to obtain permission directly from the copyright holder. To view a copy of this licence, visit http://creativecommons.org/licenses/by/4.0/. 
Routine diagnostic imaging modalities such as regional X-ray, ultrasound, and CT are not good enough because of either relatively low sensitivity or limited coverage [5]. In addition, in patients with cancer histories, work-ups focus on the patients' primary malignancies, and the coexistence of another primary malignant lesion can be missed. It is crucial to detect an additional primary malignant tumor at an early stage for the patients' sake, not only for earlier treatment, but also for more tailoring suitable therapeutic regimens. Second primary malignancy is the leading cause of treatment failure [6].

Fluorodeoxyglucose positron-emission tomography/computed tomography using Fluorine-18- (18F-FDG PET/CT) is a comprehensive imaging modality that combines anatomic and metabolic information. The whole-body 18F-FDG-PET/CT is a new imaging technology, with undoubted advantages in clinical oncology. It has expanding applications in clinical oncology with good results in cancer detection, staging, and evaluating the treatment of many tumors [7].

This retrospective study is pointing to the promising potential of FDG-PET/CT image in biopsy guidance for detecting additional primary malignant tumors in cancer patients.

\section{Methods}

This retrospective study was approved by the local Ethics Committee. From July 2015 to December 2017. Six hundred and forty-four patients with at least a known primary malignancy underwent 18F-FDG PET/CT scan in our institute for the purpose of initial diagnosis, follow-up and assessment of tumor response during therapy or surveillance.

Medical archives of these patients were analysis for detection of patients with newly developed lesions that do not follow expected patterns of spread and suspected to be additional primary. Image-guided biopsy for histopathological confirmations with immune-histochemistry in doubtful cases was used as reference stander to testify PET/CT findings.

Thirty patients (age ranging from 28 to 65 years old, 18 men and 12 women) with newly detected lesions detected during PET/CT imaging in our center were enrolled in our study.

- Inclusion criteria: PET/CT imaging prior biopsy decision for suspected additional malignant tumors of distinct histopathology

- Exclusion criteria: unconfirmed histological data and/or additional lesions suspected to be a metastasis of the first one.

\section{PET/CT scan}

\section{Patient preparation}

All patients were fasting at least $6 \mathrm{~h}$, only water was allowed, strenuous activity was avoided to decreased muscle uptake, control blood glucose level below 150 $\mathrm{mg} / \mathrm{dl}$ before injection of approximately 0.7 millicurie 18 -F-FDG intravenously (the dose was adjusted according to weight, height and random blood sugar). 40-60 min later, PET/CT scan was done. Patients were asked to void immediately prior to the scan.

- Philips NM Gemini PET/CT machine is used to scan all patients.

- Patients were asked to lay supine, hands above the heads.

\section{Scan protocol}

CT scan was done at first starting from vertex to midthigh with the following parameters: $120 \mathrm{kV}, 50 \mathrm{~mA}, 5-$ $\mathrm{mm}$-slice thickness, and $0.5 \mathrm{~mm}$ incrimination, gantry rotation speed, $0.8 \mathrm{~s}$ per rotation. Subsequently, PET scan was performed in caudo-cranial direction with 2$\mathrm{min} /$ bed position. The whole scan took 25-30 min.

\section{Post-processing}

$\mathrm{CT}$ and PET images were reconstructed at $3 \mathrm{~mm}$ thickness in 3 planes (axial, sagittal and coronal), and then fused PET/CT images were generated for visual interpretation and semi-quantitative analysis. MILLENSYS DICOM Viewer PACs system was used to facilitate image handling.

\section{Data analysis}

All medical archive (reports then scans) in PET/CT unit was evaluated separately by two radiologists (RS, 5 years experience) and (ES, 5 years experience). The observers were blinded for ultimate clinical outcomes.

Image interpretation detect additional primary malignancy as follows:

- First, visual analysis was performed with the background liver uptake as an internal reference.

- Then, physiologic FDG uptake of brain, heart, renal, and bladder should be confirmed.

- After that, any abnormal increased FDG uptake is picked up and correlated with any anatomical abnormalities at CT scan. Diagnosis in cases of tumor with poor FDG uptake depended mainly on CT features.

The standard reference was obtained from the medical records, including final pathological examinations and clinical follow-up results. 


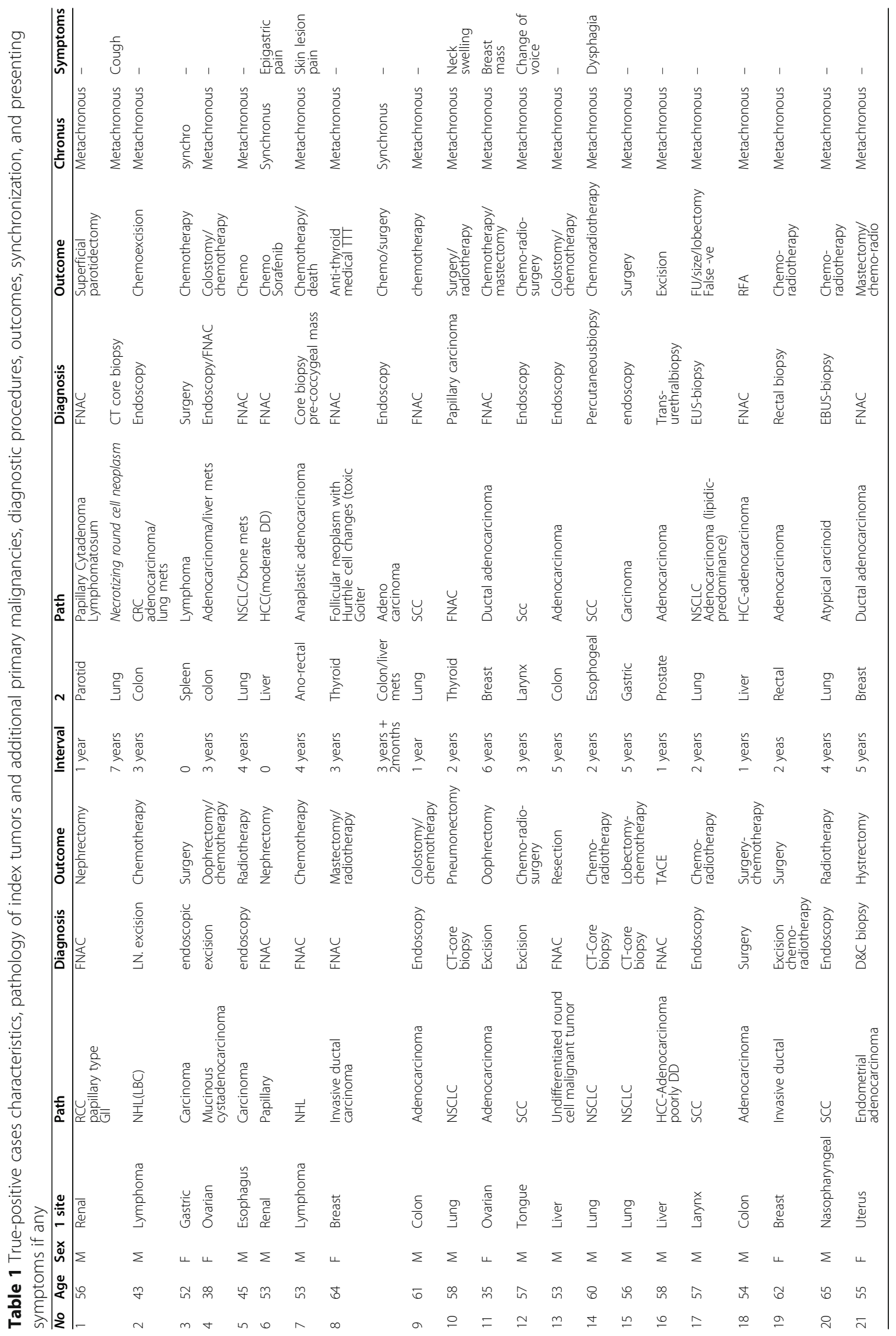


Table 2 False-positive cases characteristics, pathology of index tumors, and additional primary malignancies, diagnostic procedures, and outcomes

\begin{tabular}{|c|c|c|c|c|c|c|c|c|c|c|c|}
\hline & Age & Sex & 1 site & Path & Diagnosis & Outcome & Interval & 2 & Path & Diagnosis & Outcome \\
\hline 22 & 55 & M & Liver & $\mathrm{HCC}$ & FNAC & RFA & 0 & GB & Cholecystitis & FU/US & Medical TाT \\
\hline 23 & 35 & $\mathrm{~F}$ & Breast & $\begin{array}{l}\text { Invasive ductal } \\
\text { carcinoma }\end{array}$ & FNAC & $\begin{array}{l}\text { Lumpectomy/ } \\
\text { chemotherapy }\end{array}$ & 0 & Lung & $\begin{array}{l}\text { Post pneumonic } \\
\text { nodule }\end{array}$ & Biopsy & FU \\
\hline 24 & 32 & $\mathrm{~F}$ & Breast & $\begin{array}{l}\text { Invasive ductal } \\
\text { carcinoma }\end{array}$ & FNAC & Mastectomy/chemo-radio & $6 \mathrm{M}$ & Colon & Colitis & Endoscopy & Medical TाT \\
\hline 25 & 28 & $\mathrm{~F}$ & Colon & $\begin{array}{l}\text { Infiltrating } \\
\text { adenocarcinoma }\end{array}$ & Endoscopy & Colostomy/chemotherapy & 0 & Breast & Fibroadenoma & Excision & lumpectomy \\
\hline 26 & 32 & $\mathrm{~F}$ & Breast & $\begin{array}{l}\text { Invasive ductal } \\
\text { carcinoma }\end{array}$ & FNAC & $\begin{array}{l}\text { Lumpectomy/chemo- } \\
\text { radio }\end{array}$ & 0 & Thyroid & Thyroiditis & FNAC & Medical TाT \\
\hline 27 & 60 & M & Colon & Adenocarcinoma & Endoscopy & $\begin{array}{l}\text { Colostomy/ } \\
\text { chemotherapy }\end{array}$ & $9 \mathrm{M}$ & adrenal & $\begin{array}{l}\text { Metachronous } \\
\text { Metastasis }\end{array}$ & FNAC & chemotherapy \\
\hline 28 & 60 & $\mathrm{~F}$ & Lymphoma & $\mathrm{NHL}(\mathrm{LBC})$ & LN. excision & Chemotherapy & 0 & Parotid & $\begin{array}{l}\text { Pleo-morphic } \\
\text { adenoma }\end{array}$ & FNAC & Excision \\
\hline 29 & 45 & M & Lymphoma & $\mathrm{NHL}(\mathrm{LBC})$ & $\begin{array}{l}\text { Tissue } \\
\text { biopsy }\end{array}$ & Chemotherapy & 0 & Colon & Colitis & Endoscopy & Medical TाT \\
\hline 30 & 54 & $\mathrm{~F}$ & Lymphoma & $\mathrm{NHL}(\mathrm{LBC})$ & $\begin{array}{l}\text { Tissue } \\
\text { biopsy }\end{array}$ & Chemotherapy & 1 year & Breast & Fibroadenoma & FNAC & Excision \\
\hline
\end{tabular}

\section{Analysis of PET/CT findings}

\section{True-positive lesion}

The malignancy diagnosed from PET/CT scan in accordance with that from the pathologic results.

\section{True-negative lesion}

The malignancy was excluded from PET/CT scan in accordance with that from the pathologic results.

\section{False-positive lesion}

The malignancy diagnosed from PET/CT scan discordance with that from the pathologic results (not neoplastic or metastasis of the primary).

Table 3 Summary of index tumor in the studied patients

\begin{tabular}{cll}
\hline Primary index & Frequency & Percent \\
\hline Lung & 3 & 14.3 \\
Breast & 2 & 9.5 \\
Colon & 2 & 9.5 \\
Liver & 2 & 9.5 \\
Lymphoma & 2 & 9.5 \\
Ovarian & 2 & 9.5 \\
Renal & 2 & 9.5 \\
Esophagus & 1 & 4.8 \\
Gastric & 1 & 4.8 \\
Larynx & 1 & 4.8 \\
Nasopharyngeal & 1 & 4.8 \\
Tongue & 1 & 4.8 \\
Uterus & 1 & 4.8 \\
Total & 21 & 100.0 \\
\hline
\end{tabular}

\section{False-negative}

Malignant lesions excluded by PET/CT but malignancy detected by pathological examination.

Statistical analysis of data in terms of frequencies (number of cases) and percentages are provided when appropriate. False-/true-positive and positive predictive values and rate were calculated to test validity of PET/CT in detection of extra primary. The correlation of PET/CT findings with standard reference was analyzed using $\chi 2$ test. $P$ values $<0.05$ were considered statistically significant.

Microsoft Excel 2007 (Microsoft Corporation, NY, USA) and PASW statistics 18 (Predictive Analytics Software; SPSS Inc. PASW statistics 18, Chicago, IL, USA) were used for statistical calculations.

Table 4 Summary of the additional primary in the studied group

\begin{tabular}{lll}
\hline Additional primary & Frequency & Percent \\
\hline Colorectal & 5 & 23.8 \\
Lung & 5 & 23.8 \\
Breast & 2 & 9.5 \\
Liver & 2 & 9.5 \\
Anorectal & 1 & 4.8 \\
Gastric & 1 & 4.8 \\
Larynx & 1 & 4.8 \\
Oesophogeal & 1 & 4.8 \\
Prostate & 1 & 4.8 \\
Splenic lymphoma & 1 & 4.8 \\
Thyroid & 1 & 4.8 \\
Total & 21 & 100.0 \\
\hline
\end{tabular}




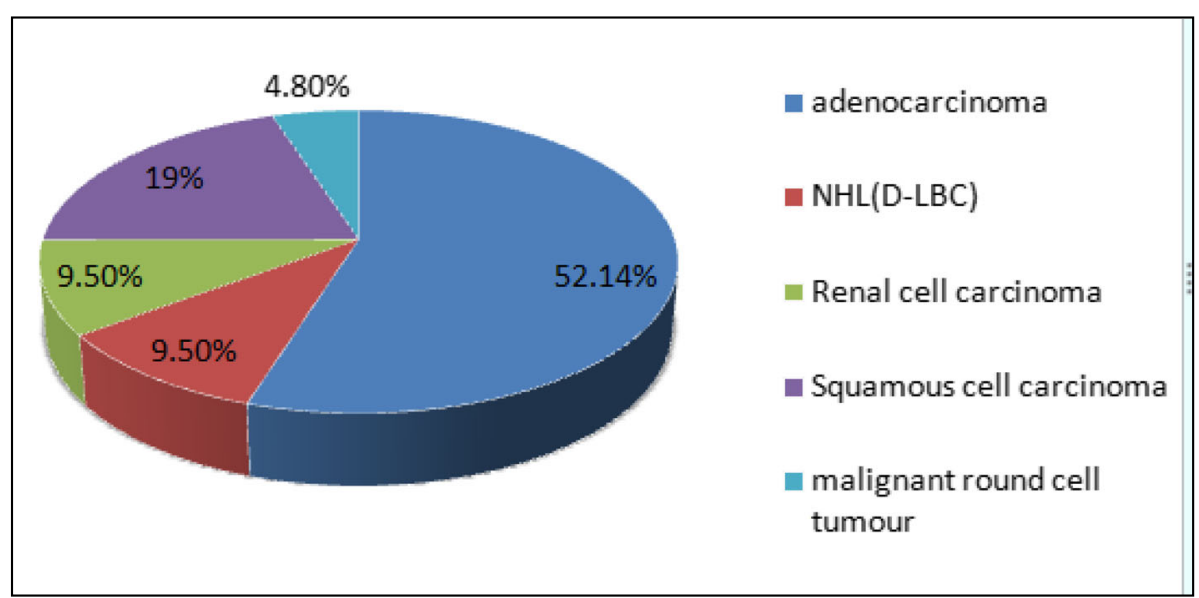

Fig. 1 The pathology of the primary tumor (pie-chart)

\section{Results}

Thirty patients enrolled in the study, age range from 28 to 65 , mean $51.2 \pm 10.47$ SD. 18 Men $(60 \%)$ and 12 women (40\%). m

Out of 30 patients, 21 patients were finally diagnosed to have additional primary malignancies (Table 1). While 9 patients were considered false-positive cases, 2 had colitis, 2 had breast fibroadenoma, 1 had metachronous adrenal metastasis in colorectal cancer 1 had parotid pleomorphic adenoma, 1 had thyroiditis, 1 had cholecystitis, and 1 had post pneumonic nodule (Table 2).

On the other hand, one patient with a history of laryngeal carcinoma displayed a negative-FDG-uptake nodule within his lung and it showed increased size during follow-up, it was finally proven to be bronchogenic adenocarcinoma with lipidic predominance after endobronchial ultrasound-guided biopsy (EBUS), which was considered to be a false-negative case in this study.

In total, true positive cases were 21 patients with proven additional primary malignancies in this study.
Therefore, the sensitivity of PET/CT for diagnosing additional primary malignancy in the study was $95.23 \%$ (20/ $21)$, the PPV was $68.97 \%(20 / 29)$, and the false-positive rate was $31 \%(9 / 29)$.

The pathology of the index tumors was adenocarcinoma (12/21, 57.14\%), NHL D-LBC type (2/21, 9.5\%), renal cell carcinoma papillary type $(2 / 21,9.5 \%)$ Squamous cell carcinoma $(4 / 21,19 \%)$ and undifferentiated malignant round cell tumor of the liver (1/21, 4.8\%) (Fig. 1).

Gastro-intestinal tract malignancies (colon, esophageal, and gastric) had the highest incidence to develop additional primary tumor in the current study, represented $19.05 \%$ (4/21 patients) of cases followed by lung cancer $(3 / 21,14.29 \%)$ and head and neck malignancies (laryngeal, nasopharyngeal, and tongue cancer (3/21, 14.29\%) (Table 3).

Gastro-intestinal tract malignancies (5 cases had colorectal cancer, 1 case had anorectal cancer, 1 case had oesophageal cancer) is the most common additional malignancy in this study $(8 / 2138.1 \%)$, followed by lung

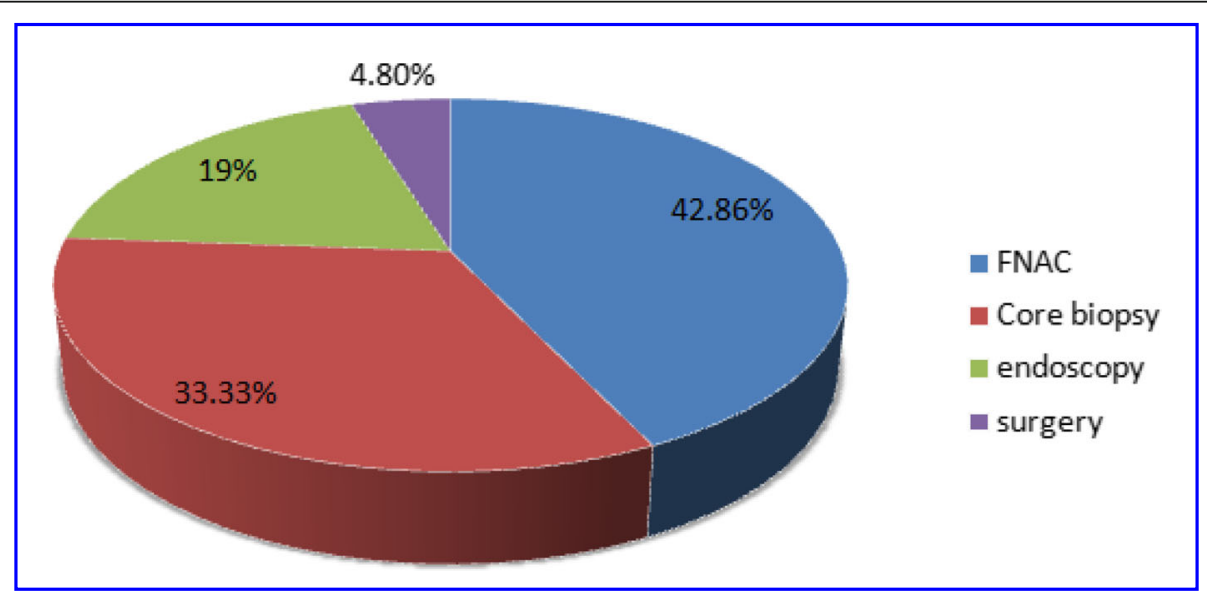

Fig. 2 Types of biopsy (diagnostic procedure) of extra malignancy in the studied group (pie-chart) 

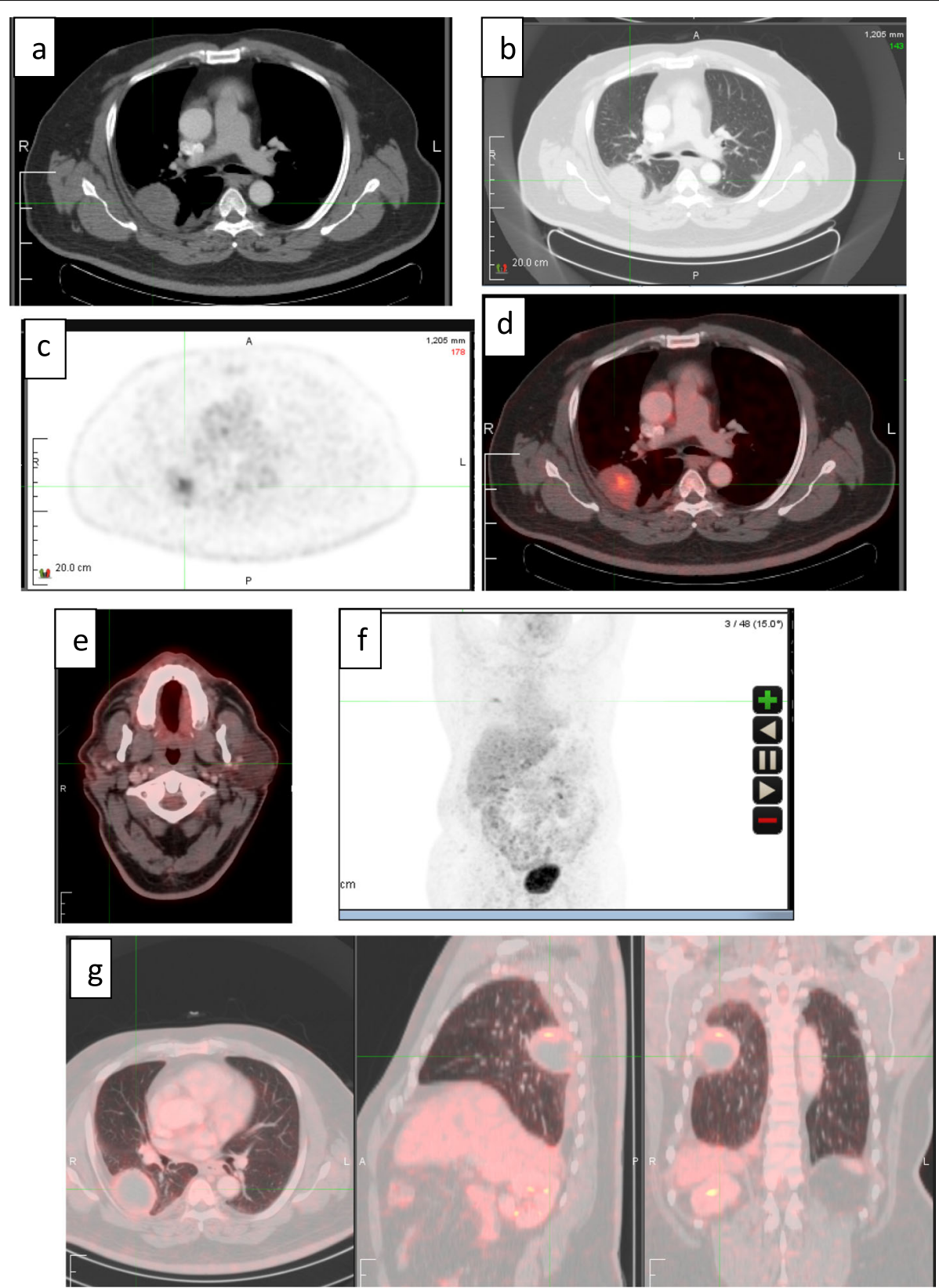

Fig. 3 A 56-year-old male underwent left nephrectomy for renal cell carcinoma papillary type, grade II and superficial parotidectomy for papillary cytadenoma lymphomatosum. CT (a, b), PET (c), and PET/CT (d) revealed metabolically active necrotizing right pleural-based malignant pulmonary mass in the apical segment of right lower measuring $6.2 \times 5 \mathrm{~cm}$ SUVmax 4.8, no regional lymphadenopathy or distant metastasis. CTguided core biopsy revealed necrotizing round cell neoplasm. PET/CT (e) reveals clear operative beds with no metabolically active residual/ recurrent parotid tumor. MIP PET (f) image confirm the previous findings. PET/CT (g) shows newly detected lung cancer in 3 planes

cancer $5 / 21,23.8 \%$, then breast cancer and HCC $(2 / 21$, 9.5\%) each. Site and percentage of additional malignancies displayed in table (Table 4).

Diagnosis conducted by FNAC in $(9 / 21,42.86 \%)$ and endoscopy in $(7 / 21,33.33 \%)$, core biopsy $(4 / 21,19 \%)$ and surgery in $(1 / 21,4.8 \%)$. Pie chart illustrated the diagnostic mean of additional primary (Fig. 2).
Two patients in the study had two different primary malignancies from the start, the third primary that detected by PET/CT was considered the additional malignancy in the study [Patient number 1 and number 8] (Figs. 3 and 4).

Among these 21 patients, 14 patients were without any related symptoms that are indicative of second 

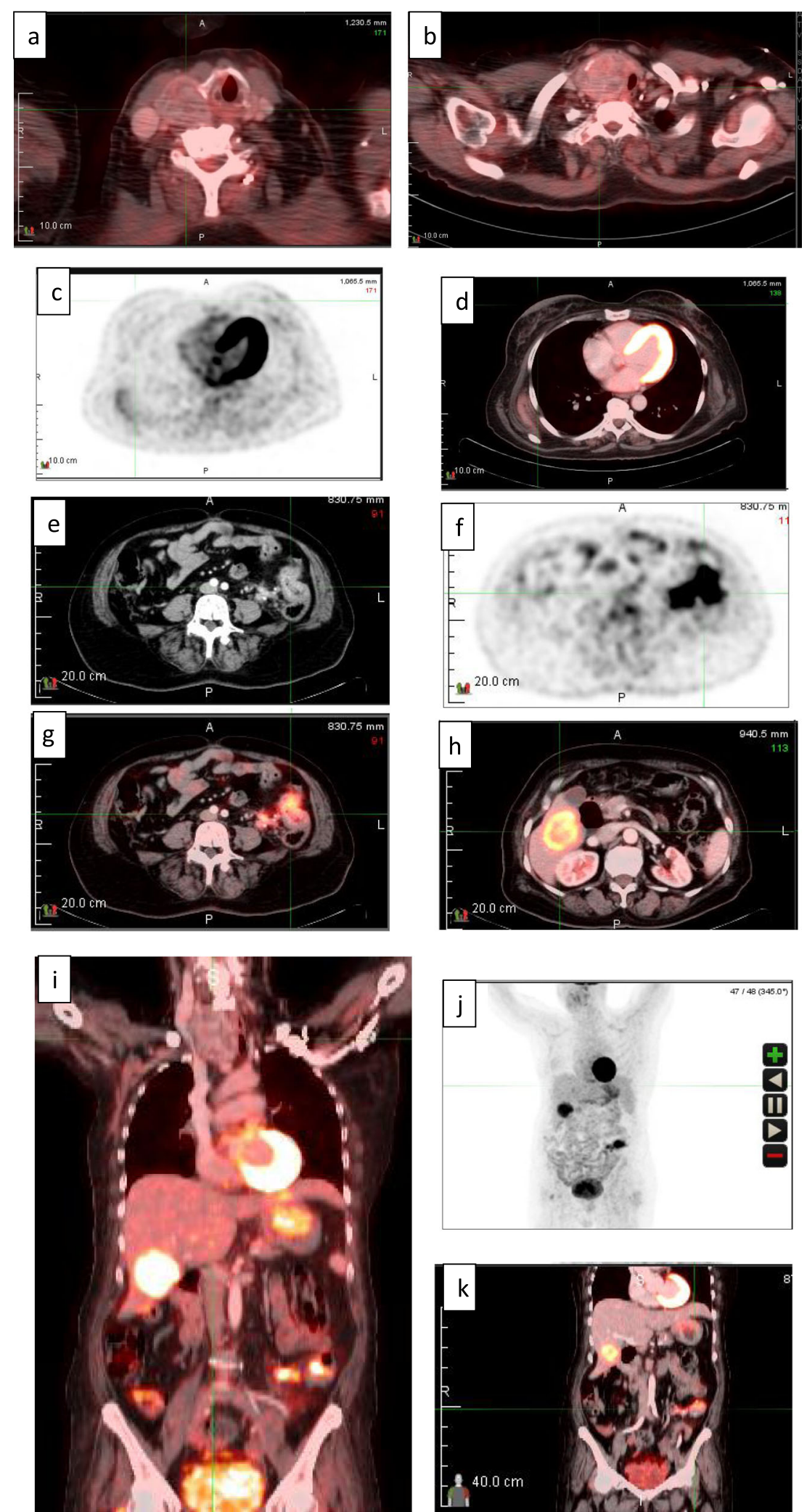

Fig. 4 (See legend on next page.) 
(See figure on previous page.)

Fig. 4 A 64-year-old female patient with right breast cancer underwent lumpectomy and received radiotherapy with a large toxic thyroid nodule confirmed to be a follicular neoplasm with Hurthle cell changes, patients receive anti-thyroid drugs. PET/CT $(\mathbf{a}, \mathbf{b})$ revealed enlarged right thyroid lobe showing a solid nodule $(45 \times 38 \times 67 \mathrm{~mm})$ with foci of macro-calcifications and areas of cystic degenerations, no significant abnormal increased FDG utilization. CT \& PET (c, d) shows clear surgical bed of breast, the overlying skin is still diffusely thickened. CT (e), PET (f), and PET/CT ( $\mathbf{g}-\mathbf{k})$ show metabolic active right hepatic lobe focal lesion is SUVmax. 10.5. Diffuse increased tracer fixation is seen in a segment of descending colon, measuring about $60 \mathrm{~mm}$ with focal circumferential mural thickening SUVmax. 8.1. Colonoscopy and biopsy revealed rectal infiltrating adenocarcinoma

primary malignancies, while the other 7 patients had symptoms thought to be metastasis/tumor recurrence.

FDG standardized uptake value (SUV) max varied widely between the primary and additional malignancy, the highest SUV max detected in patient with non-Hodgkin lymphoma diffuse large $\mathrm{B}$ cell type (NHL-D/LBC), SUVmax 22 in lymphomatous LNs and 10 in hepatic deposits from colonic mass with SUVmax 8.8 (Fig. 5).

Synchronous diagnosis of additional malignancy in the studied patients detected in 3/21 (14.29\%) of patients (Fig. 6). Metachronous diagnosis of extra malignancy noticed in $(18 / 21 ; 85.80 \%)$ with the longest interval of 7 years.

\section{Discussion}

With the improved diagnostic techniques of cancers patients, sophisticated treatment, increased survival, and life expectancy; the higher frequency of multiple primary malignant neoplasms are noticed [8].

Multiple primaries are defined as two or more unrelated primary malignant tumors of distinct histology and occur in the body at the same time or one after another. Synchronous primaries diagnosed in an interval of fewer than 6 months. Risk of developing an additional primary malignancy is varying because of the variable evaluation period and the inclusion criteria [5].

$\mathrm{PET} / \mathrm{CT}$ is superior to conventional imaging for staging and restaging of most cancers. CT component provides the anatomical framework within which the biology of cancer can be visualized by PET. This powerful combination is a well-established tool in diagnostic work up of cancer patients [9].

In the current study, with the use of PET/CT imageguided biopsy, sensitivity for diagnosing additional primary malignancy is $95.23 \%(20 / 21)$, the PPV was $68.97 \%$ (20/29), and the false-positive rate was $31 \%(9 / 29)$ in concordance to study of Haoping Xu et al. [6] who had showed nearly the same sensitivity of $95.24 \%$ and higher PPV of $74.07 \%$.

The detection rate in this study (3.26\%) in relatively in concordance to Ali et al. [10], who had shown similar detection rate 13 out of 273 patients (4.76\%) with the lower PPV of $56.5 \%$ and sensitivity of $89.2 \%$ and discordance to Servente et al. [11] who showed less detection rate $(1.2 \%, 49 / 4086)$ and Tibana and Lee $[3,12]$ who had shown lesser detection rate (1.1).

In the current study, the most frequent primary neoplasm were lungs $(n=3)$ followed by breast $(n=$ 2 ) and colon $(n=2)$ in discordance to study of Servente et al. [11] who founded the most common index tumors: breast $(n=27)$, lung $(n=27)$, and colorectal $(n=20)$ and study carried by Ishimori et al. [13] who found the foremost known primary tumors included lung (28.6\%), colon or rectum $(12.4 \%)$, and head or neck (12.1\%).

Multiple primaries in patients with lung cancer are related to smoking, no association with radiotherapy [14], highest in small cell lung cancer (SCLC), squamous cell carcinoma, and fewer in adenocarcinoma. The most common second cancers are in the lung (adenocarcinoma $<$ SCC < SCLC), colorectal, and bladder cancers [15].

Various factors contribute to the occurrence of multiple primaries in breast cancer; hormonal treatment of primary breast cancer (esp. Tamoxifen therapy) that increases the risk for endometrial, gastric, colon, and ovarian cancers [16]. Genetic factors (e.g., BRCA1, BRCA2) and obesity may increase the hazard for a second breast or ovarian cancer. Hereditary factors increase the risk gastric cancer and lobular breast cancer. Premenopausal increases risk of second breast, endometrial or ovarian cancer. Radiotherapy and chemotherapy increase the risk for a secondary primary in breast cancer, thyroid cancer, bone, connective tissue, and lung [17].

\section{Multiple primaries in lymphoma}

Radiation therapy has an increased risk for breast, lung, thyroid, and colorectal cancers. Chemotherapy is associated with an increased risk for leukaemias and lung, gastrointestinal or bladder cancer, soft tissue, and bone sarcomas.

In this study, the foremost common location of the second primary tumor was colon $(n=5)$ and lung $(n=$ $5)$ in concordance to Servente et al. [11] who histologically confirmed second primary in colon $(n=18)$, lung $(n=6)$, breast $(n=6)$, and in discordance to study of Tibana et al. [3] who found most common sites of the additional malignancies were the lung $(n=4)$, kidney $(n$ $=3)$, and prostate $(n=2)$.

There were 28 false-positive findings in the study of to Servente et al. [11] compared to the result of this study, in which only 9 false-positive findings detected. 

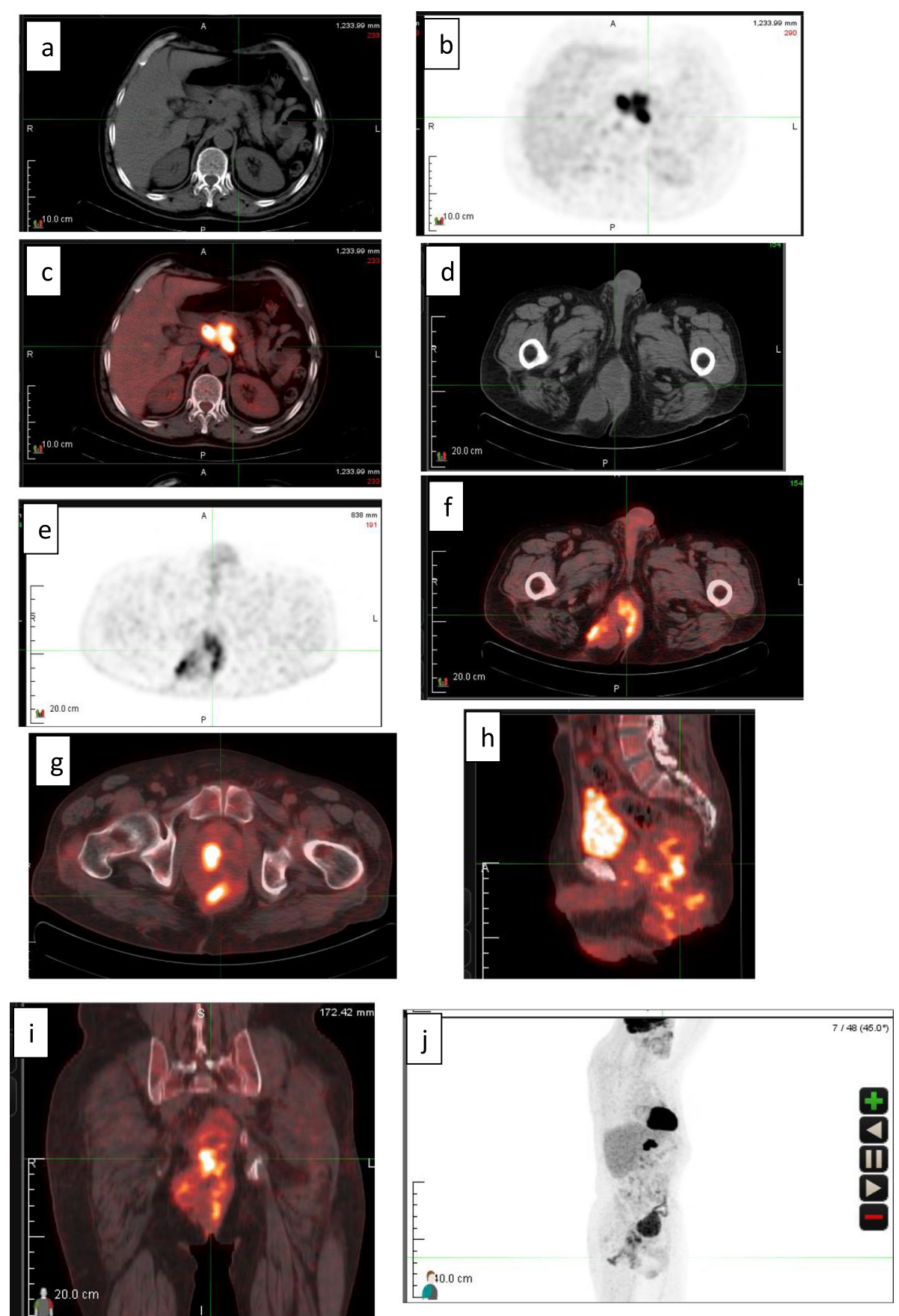

Fig. 5 A 53-year-old male patient with NHL- diffuse large B cell type underwent splenectomy and received chemotherapy presented by peri-anal swelling. CT (a), PET (b), and PET/CT (c) revealed FDG- avid peri-pancreatic/caeliac LNs with each other are also seen and measures about (6.2 $\times$ $4.8 \mathrm{~cm}$ ) with SUV 22). CT (d), PET (e), and PET/CT (f-i) show metabolically active pre-coccygeal mixed cystic and solid soft tissue mass with few calcific foci seen inside, infiltrating the posterior and lateral walls of the rectum and anal canal encroaching upon the posterior aspect of the colon, and the prostate and extends to the overlying skin and subcutaneous tissue of the gluteal region and measures about $8.7 \times 7.5 \times 16 \mathrm{~cm}$ in dimensions with inhomogeneous FDG tracer fixation of its solid components and SUVmax 10.6. MIP PET image (j) confirms the findings. USguided core biopsy of pre-coccygeal mass on revealed anaplastic adenocarcinoma and patient received chemotherapy

Additional primary malignancy is suspected when abnormal FDG uptake in unusual site of metastasis or not follow the usual sequence of metastasis. For example, in breast cancer patients, an additional primary lung cancer is considered when an isolated pulmonary lesion is found in the absence of usual sequence of metastasis (axillary LNs, hepatic, or bone lesions), in addition, lung metastasis is rounded in appearance with relatively smooth 

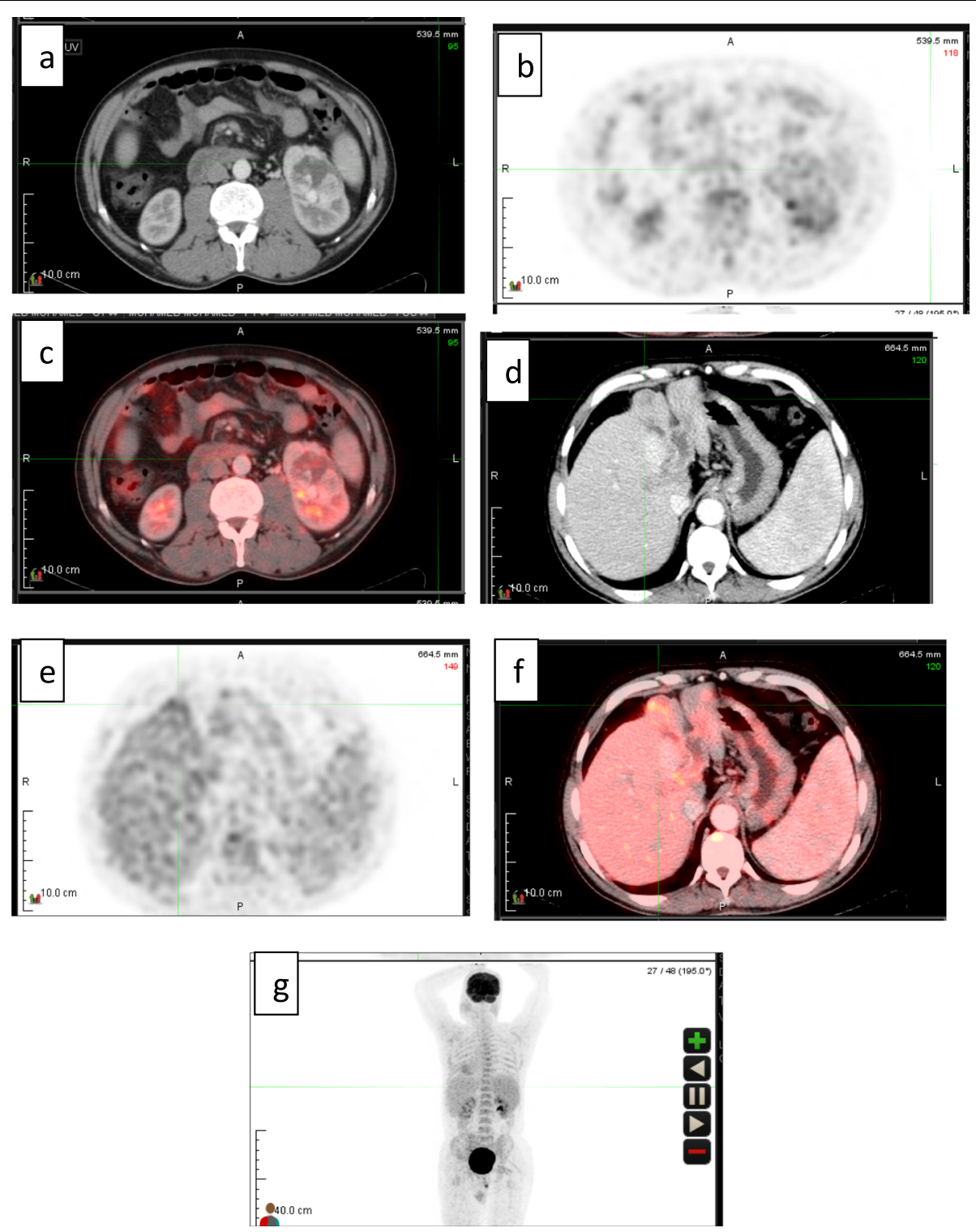

Fig. 6 A 53-year-old male patient with sever epigastric pain referred to the back. US revealed cirrhotic liver changes with diffuse infiltrative mass seen at the left lobe. CT (a), PET (b), and PET/CT (c) revealed left renal solid mass measuring $(5.8 \times 5.8 \mathrm{~cm})$ with central area of breakdown, the mass is invading the cortex and medulla, displacing and distorting the renal calyces and avid contrast enhancement, mild abnormal increased tracer fixation, patent renal vein. CT (d), PET (e), PET/CT (f), and MIP PET (g) revealed ill-defined infiltrative mass seen at the left lobe segment IV with mild increased tracer utilization. Dilated partially thrombosed portal vein trunk and left branch with enhancement thrombus during arterial phase. Biopsy revealed renal cell carcinoma papillary type grade II and infiltrative HCC

margins, while a primary pulmonary malignancy appears spiculated or ground glass in appearance [17]. The usual sequence of metastasis in non-small cell lung cancer follows this orders LNs, adrenal glands, liver, bone, and brain [9]. The most common site of metastasis in squamous cell carcinoma of the head and neck is lung [8].

Synchronous malignancies within the upper digestive and respiratory tract related to the carcinogenic effects of alcohol and tobacco [18].
In spite the fact that false-positives can occur with FDG PET/CT, the predominance of true-positives cannot be belittled. Extra primary malignancies identified by $\mathrm{PET} / \mathrm{CT}$ increases the probability of remedy if such malignancies are treated promptly and forcefully.

\section{Limitations of the study}

Limited sample size as the study conducted in single center, uncertain as to whether study patients were representative of all target population. 


\section{Selection bias}

Study concerned with positive lesions in PET/CT, Negative cases could not attract attention to follow up and take biopsy to validate negative cases.

\section{Study design}

While prospective study allows comparing the independent roles of PET, CT components, unfortunately, this study is retrospective.

The study in concerned with additional malignancy whatever the primary, this makes it difficult to analyze link between the different primaries in full details, but in brief.

\section{Conclusions}

With the use of 18-F FDG PET/CT image-guided biopsy, additional primary malignancies were detected in at least $3.26 \%$ of oncology patients; thus, patient cure is possible if such malignancies are treated promptly and aggressively.

\section{Abbreviations}

18-F-FDG PET/CT: Fluorodeoxyglucose positron-emission tomography/computed tomography utilizing fluorine-18; PPV: Positive predictive value; SEER: Surveillance, Epidemiology, and End Results; IACR/IARC: Program and the International Association of Cancer Registries and International Agency for Research on Cancer; SUV: Standardized uptake value; NHL-D/LBC: NonHodgkin lymphoma diffuse large B cell type

\section{Acknowledgements}

Special thanks to our colleagues and seniors in the hospital for general support.

\section{Authors' contributions}

ES collected the data, analyzed and interpreted the patient data, performed the statistical analysis of results, and was a major contributor in writing the manuscript. RS wrote part in the discussion. All authors read and approved the final manuscript.

\section{Funding}

Not applicable

\section{Availability of data and materials}

The datasets used and/or analyzed during the current study are available from the corresponding author on reasonable request.

\section{Ethics approval and consent to participate}

Ethical approval was obtained by Tanta University Ethics committee. Committee's reference number: Not applicable. All participants enrolled in the study provided informed verbal consent to participate.

\section{Consent for publication}

All patients included in this research gave informed consent to publish the data contained within this study.

\section{Competing interests}

Authors declare no competing interests.

Received: 12 May 2020 Accepted: 14 September 2020

Published online: 06 October 2020

\section{References}

1. Miller KD, Nogueira L, Mariotto AB, Rowland JH, Yabroff KR, Alfano CM et al (2019) Cancer treatment and survivorship statistics, 2019. CA: a cancer journal for clinicians 69:363-385
2. Copur MS, Manapuram S (2019) Multiple Primary Tumors Over a Lifetime. Oncology 33

3. Tibana TK, Santos RFT, Arao FA, Bacelar B, Martins LA, Souza RO et al (2019) Detection of additional primary malignancies: the role of CT and PET/CT combined with multiple percutaneous biopsy. Radiologia brasileira 52:166-171

4. Bowman EM, Oza UD, Latifi HR (2011) Utility of pattern recognition in the detection of unsuspected additional primary malignancies on positron emission tomography-computed tomography. Proceedings (Baylor University. Medical Center) 24:210-215

5. Vogt A, Schmid S, Heinimann K, Frick H, Herrmann C, Cerny T et al (2017) Multiple primary tumours: challenges and approaches, a review. ESMO open 2:e000172

6. Xu H, Zhang M, Zhai G, Li B (2010) The clinical significance of 18F-FDG-PET/ $\mathrm{CT}$ in early detection of second primary malignancy in cancer patients. J Cancer Res Clin Oncol 136:1125-1134

7. Saif MW, Tzannou I, Makrilia N, Syrigos K (2010) Role and cost effectiveness of PET/CT in management of patients with cancer. Yale J Biol Med 83:53-65

8. Etiz D, Metcalfe E, Akcay M (2017) Multiple primary malignant neoplasms: A 10-year experience at a single institution from Turkey. J Cancer Res Therapeutics 13:16-20

9. Takada K, Toyokawa G, Yoneshima Y, Tanaka K, Okamoto I, Shimokawa M, et al. (2019) (18)F-FDG uptake in PET/CT is a potential predictive biomarker of response to anti-PD-1 antibody therapy in non-small cell lung cancer. Scientific reports 9:13362.

10. Ali SA, Hamed MA (2017) The diagnostic efficacy of whole body 18F-FDG PET CT in detection of unexpected second primary malignancy in cancer patients. Egypt J Radiol Nuclear Med 48:671-676

11. Servente L, Bentancourt C, Alonso O (2019) Detection of Unexpected Malignant/Premalignant Tumor on 18F-FDG PET/CT Imaging in Cancer Patients. Revista Argentina de Radiología 83:3-11

12. Lee JC, Teles MS (2019) Prevalence of additional primary malignancies detected incidentally on PET/CT. Radiologia brasileira 52:348

13. Ishimori T, Patel PV, Wahl RL (2005) Detection of unexpected additional primary malignancies with PET/CT. J Nuclear Med 46:752-757

14. Sánchez de Cos Escuín J, Rodríguez López DP, Utrabo Delgado I, Gallego Domínguez R, Sojo González MA, Hernández Valle M (2016) Disease Recurrence and Second Tumors in Long-term Survivors of Lung Cancer. Archivos de bronconeumologia 52:183-188

15. Bhaskarla A, Tang PC, Mashtare T, Nwogu CE, Demmy TL, Adjei AA et al (2010) Analysis of second primary lung cancers in the SEER database. J Surgical Res 162:1-6

16. Ricceri F, Fasanelli F, Giraudo MT, Sieri S, Tumino R, Mattiello A et al (2015) Risk of second primary malignancies in women with breast cancer: Results from the European prospective investigation into cancer and nutrition (EPIC). Int J Cancer 137:940-948

17. Li Z, Wu Q, Song J, Zhang Y, Zhu S, Sun S (2018) Risk of Second Primary Female Genital Malignancies in Women with Breast Cancer: a SEER Analysis. Hormones Cancer 9:197-204

18. Guo R, Li N, Wang F, Fan Y, Zhao W (2018) Application of 18F-FDG PET/CT in patients with synchronous multiple primary carcinoma. Tumor 38:371-378

\section{Publisher's Note}

Springer Nature remains neutral with regard to jurisdictional claims in published maps and institutional affiliations. 